\title{
Cooperative Trial in Diagnostic Imaging
}

National Cancer Institute

\section{Source}

National Cancer Institute. Cooperative Trial in Diagnostic Imaging. NCI Thesaurus. Code C15947.

A single national Network of investigators that will perform multi-institutional clinical trials in diagnostic imaging related to cancer. The Network will have the capability to conduct a broad spectrum of clinical trials in imaging. This Network will generate new trials in areas of high scientific opportunity. The Network will consist of a Headquarters office that coordinates operations, a Biostatistics and Data Management Center (BDMC), and a number of participating institutions in which the studies are performed. Participating institutions will be selected by the Network's scientific leadership for their ability to contribute to the particular trials in the Network's research repertoire. 